\section{An Unusual Endoscopic Procedure to Remove a Toothbrush from the Stomach}

Endoscopic removal of swallowed toothbrushes has been reported in patients with disturbed behavior $(1,2)$. The brushes, larger than $10 \mathrm{~cm}$ in size, may stop in an area of anatomic narrowing and cause bowel perforation, bleeding or obstruction, requiring removal by surgery (2). We describe here the successful endoscopic removal of a toothbrush from the stomach using a Dormia basket.

A 26-year-old woman with no history of mental illness presented to the emergency department and stated that she had accidentally swallowed the toothbrush when carrying out dental care. She was asymptomatic. A plain abdominal radiograph confirmed the presence of a foreign body in the left upper quadrant (Figure 1). During gastroscopic examination (Olympus GIF-XQ10), the toothbrush was visualized in the stomach. Endoscopic removal was carried out after premedication with midazolam. The head of the brush was in the fundus, and the handle was close to the small curvature of the gastric body. The toothbrush, $16 \mathrm{~cm}$ in length, was removed using a Dormia basket. Once the head of the toothbrush had been grasped, we pushed it up to align it with the axis of the esophagus (Figure 2). We had no difficulty in passing it through the gastroesophageal junction. Once the toothbrush head reached the oropharymx we byperextended the patient's neck and with the help of two fingers, pulled the brush out in one motion. The entire procedure required about three minutes, and took place without complications. A control endoscopic examination showed no mucosal lacerations. The patient was discharged three hours later without complaints.

The endoscopic removal of elongated objects is often difficult, delayed, and can be dangerous, since such objects tend to become lodged in the hypopharynx, or to escape into the larynx and trachea. Almost all the cases reported used an overtube, or orotracheal intubation under general anesthesia for safety, avoiding surgery (3). Only one published case describes extraction using a Dormia basket (2). An exception was a toothbrush removed from the duodenum by a rat-tooth forceps inserted through a hole in the handle of the brush (4). The only complication ever described was an esophageal perforation (5). A case was reported of a toothbrush passing the gastrointestinal tract without complication, and there was another case of removal by gastrotomy (1). Biopsy forceps, foreign-body forceps, and polypectomy snares are usually of no use, since the toothbrushes are covered with mucus, which makes it difficult to trap the bristles.

The case described here shows that, in a cooperative patient, it is possible to remove a toothbrush from the stomach endoscopically, with no special accessories apart from the Dormia basket itself, and without any injury.

\section{Bastos, D. Gomes, I. Cotrim, H. Gouveia, A. Donato, \\ D. de Freitas}

Dept. of Gastroenterology, University Hospital of Coimbra, Coimbra, Portugal

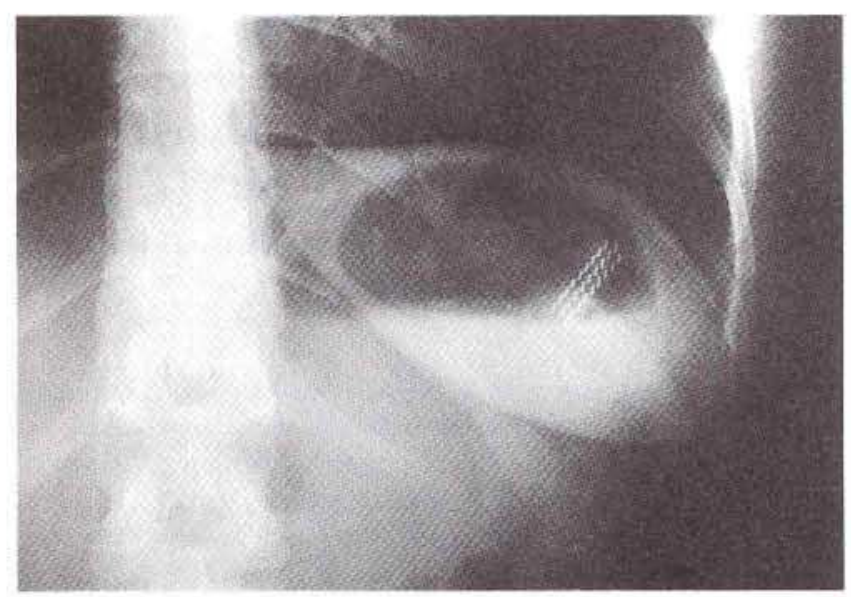

Figure 1: Radiopaque bristle receptacles (linear metallic densities) in the toothbrush in the fundus of the stomach.

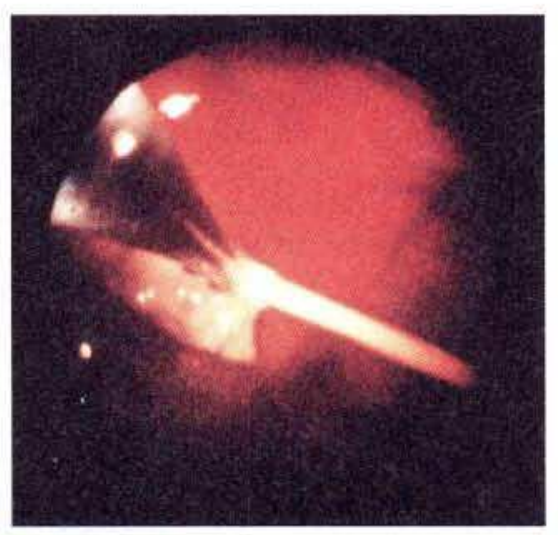

Figure 2: Endoscopic removal, with the head of the toothbrush grasped by a Dormia basket.

\section{References}

1. Riddlesberger MM, Cohen HL, Glick PL. The swallowed toothbrush: a radiographic clue of bulimia. Pediatr Radiol 1991; $21: 262-4$.

2. Vantsian EN, Krendal AP. Two rare cases of endoscopic extraction of foreign bodies from the stomach and duodenum. Endoscopy 1984; 16:242-5.

3. Chinitz MA. Bertrand G. Endoscopic removal of toothbrushes. Gastrointest Endose 1990; 36; 5: 527-30.

4. Ertan A, Kedia SM. Agrawal NM, et al. Endoscopic removal of a toothbrush. Gastrointest Endose $1983 ; 29 ; 2: 144-5$.

5. Selivanov V. Sheldon GF, Cello JP, et al. Management of foreign body ingestion. Ann Surg 1984; 199; 2: 187-91.
Corresponding Author
I. Bastos, M.D.
Serviçe de Gastrenterologia
Hospitais da Universidade de Coimbra 3000 Coimbra
Portugal 